\title{
Interactive comment on "Performance of post-processing algorithms for rainfall intensity measurements of tipping-bucket rain gauges" by Mattia Stagnaro et al.
}

\author{
Mattia Stagnaro et al. \\ mattia.stagnaro@unige.it \\ Received and published: 25 October 2016
}

We would like to thank referee 4 for his/her comments since they allowed us to improve the quality of the manuscript.

Please, see the attached pdf file containing our answers to the referee comments.

Please also note the supplement to this comment:

http://www.atmos-meas-tech-discuss.net/amt-2016-257/amt-2016-257-AC4-

supplement.pdf

Interactive comment on Atmos. Meas. Tech. Discuss., doi:10.5194/amt-2016-257, 2016. 